\title{
The effect of guidance booklet on knowledge and attitudes of nurses regarding disaster preparedness at hospitals
}

\author{
Gehan Mohammed Diab *, Sohair M. Mabrouk \\ Department of Nursing Administration, Faculty of Nursing, Menoufia University, Al Minufya, Egypt
}

Received: May 17, 2015

DOI: $10.5430 /$ jnep.v5n9p17
Accepted: May 29, $2015 \quad$ Online Published: June 10, 2015

URL: http://dx.doi.org/10.5430/jnep.v5n9p17

\begin{abstract}
Background: Disasters have a potential of producing mass casualties thereby straining the health care systems. This means that hospitals need to be prepared for an unusual increase in workload, hence the importance of hospital disaster preparedness. Aim: The aim of the study to evaluate the effect of a guidance booklet on knowledge and attitude about disaster preparedness among nurses.

Methods: Research design: A quasi experimental research design with pre-test post-test time series and follow up assessment. Setting: the study was conducted at University Hospital, in Menoufia Governorate, Egypt. Subjects: The convenience sample, it include all nursing managers (nursing directors and nursing supervisors $n=12)$, all head nurses $(n=48)$ and staff nurses ( $n=$ 280), available at the time of the study. They have all fulfilled the eligibility criterion of a working experience of not less than one year of the study settings. Tools of data collection: Two tools were used for data collection. Tool one: consists of three parts; part (a) to collect socio-demographics data and part (b) aimed to collect nurses' knowledge about general disaster, classification and disaster preparedness and part (c) aimed to assess the nurses' awareness by hospital disasters on external or internal level. Tool two: Attitudes of nurses towards disaster management plan.

Results: The results of this study showed that, majority of nurses scored weak estimation in knowledge, awareness and attitudes level at pre-test measurement. Conversely, lowest percentages had moderate level, and good level of knowledge related to general disaster, while only $12.6 \%$ of nurses were satisfactory awareness about hospital disaster preparedness and $37.5 \%$ had positive attitude towards disaster management. There was statistically-significant $(p<.001)$.

Conclusions: It was concluded that, guidance booklet was successful in achieving significant improvement in nurses' knowledge regarding disaster preparedness which was reflected in improvement and changing their attitude towards disaster. Recommendation: Continued nursing education should be open to all hospital staff according to their needs to increase their awareness about disaster preparedness.
\end{abstract}

Key Words: Guidance booklet, Hospital disaster, Knowledge, Awareness, Attitude, Nurses

\section{INTRODUCTION}

A disaster situation is a serious disruption of a society that involves a big number of victims. Such an incident, affects hospitals of all sizes and geographic locations. Disasters occur daily throughout the world, posing severe public health threats and resulting in tremendous impact in terms of deaths,

\footnotetext{
*Correspondence: Gehan Mohammed Diab; Email: diabgehan@yahoo.com; Address: Department of Nursing Administration, Faculty of Nursing, Menoufia University, Al Minufya, Egypt.
} 
injuries, infrastructure and facility damage and destruction, suffering, and loss of livelihoods. Therefore, human beings must find ways to survive and minimize the damages caused by disasters. ${ }^{[1]}$ However, it is also important to note that disasters are not only caused by natural events, but also by human actions. It is with this in mind that disaster risk reduction measures should be put in place to help communities cope and minimize the impact of the disasters. ${ }^{[2,3]}$

A disaster is defined by the International Strategy for Disaster Reduction and World Health Organization as "A serious disruption of the functioning of a community or a society causing widespread human, material, economic or environmental losses which exceed the ability of the affected community or society to cope using its own resources". ${ }^{[4,5]}$ The International Federation of Red Cross and Red Crescent Societies defined disasters as "A sudden, calamitous event that seriously disrupts the functioning of a community or society and causes human, material, and economic or environmental losses that exceed the community's or society's ability to cope using its own resources, though often caused by nature, disasters can have human origins". ${ }^{6]}$ Disaster can be defined as a sudden extraordinary event that brings great damage, loss, destruction and injury to people and their environment. ${ }^{[7]}$

Disaster preparedness is essential to providing adequate health care and addressing the humanitarian challenges of disasters. The hospital disaster preparedness has therefore taken on an increased importance at local, state and national levels. ${ }^{[2]}$ Hospitals would be among the first institutions to be affected after a disaster, natural or man-made. Because of the heavy demand placed on their services at the time of a disaster, hospitals need to be prepared to handle such an unusual workload. This necessitates a well documented and tested disaster management plan to be in place in every hospital. To increase their preparedness for mass casualties, hospitals have to expand their focus to include both internal and community-level planning. ${ }^{[8]}$

At the end of the 20th century, national thinking about emergency preparedness led to two important developments: identification of the key competencies needed for effective emergency response, and increased attention to planning for and practicing emergency response. Effective response requires a disciplined team in which each participating individual follows clear lines of communication and performs according to clearly assigned role directions. ${ }^{[9]}$

Disaster Preparedness is defined as activities and measures taken in advance of an event to ensure effective response to the impact of hazards. The objective of disaster preparedness is to ensure that appropriate systems, procedures, and resources are in place to provide prompt, effective assistance to disaster victims, thus facilitating relief measures and rehabilitation of services. Disaster preparedness efforts include the identification of possible health scenarios based on the probability of hazards and vulnerability of the population as a basis for creating a disaster plan. ${ }^{[10]}$

According to hospital involvement, disasters may be classified into internal disasters that occur inside the health care facility or external disasters that occur outside the health care facility. ${ }^{[11]}$ These two types of disasters are independent, but not mutually exclusive, which internal disasters are isolated to the hospitals and occur more frequently than do external disasters. ${ }^{[12]}$ The hospital should always be prepared with written disaster plan that responds to external disasters to help in providing assistance to victims, the hospital is also vulnerable to disasters directly occurring within its walls; so preparation must be made in response to internal disasters, the most common of all is fire. ${ }^{[13]}$ A disaster plan is a systematic procedures that clearly detail what needs to be done how, when, and by whom- before and after the time an anticipated disastrous event occurs. ${ }^{[14]}$

Disaster management by nature is an interdisciplinary, collaborative team effort. Nurses collaborate with other experts, including environmentalists, epidemiologists, laboratory workers, biostatisticians, physicians, social workers and many others. ${ }^{[15]}$ Nurses have been a part of disaster preparedness; Nurses should be equipped with the necessary knowledge and abilities to work in a disaster and to meet the needs of the respective serving community. ${ }^{[16]}$ Today's nurses are faced with the challenges of responding to natural, man-made, and technological disasters and there is a lack of emergency preparedness content in the curriculum in nursing schools. ${ }^{[17]}$ The need for qualified nurses ready to respond to disasters and to participate in preparedness and disaster recovery activities is well documented and to beat this problem, necessary continuous developing specialized education and training. ${ }^{[2,18]}$ It was recommended by the World Health Organization (WHO) that all nations, no matter how frequent or infrequent the happenings, should prepare healthcare workers for a disaster. Nevertheless, most nurses were inadequately prepared for disaster and it is only through education and training can nurses can be equipped with the competencies required during disasters. ${ }^{[19]}$

Disaster education for all nurses is vital and all curricula in the nursing and medical schools have issues in emergency and disasters that would go a long way in improving knowledge and skills related to disasters. ${ }^{[2,20]}$ The dealing with the complexity of disasters requires that each nurse acquire a knowledge base and minimum set of skills to enable them 
to plan for and respond to a disaster in a timely and appropriate manner. ${ }^{[21]}$ So that the present study was developed to identifying nurses' needs regarding disaster preparedness by determine the level of nurses' knowledge, awareness and attitude about disasters' preparedness.

\subsection{Significance of the study}

Based on experience during working at university hospitals, it has been observed that nurses rarely even knew about the disaster preparedness plans in their hospital and not aware of the procedures that exist for dealing with disasters. Furthermore, there was also a lack of research available on electronic databases regarding disaster preparedness and planning in Menoufia Governorate. This study contributes to the knowledge base on hospital disaster preparedness in Menoufia Governorate. It is anticipated that the Hospitals authorities will utilize the results of the study. It will enable them to gain a better understanding of the process of disaster preparedness in the health sector in order to strengthen the capacities and capabilities of hospitals in Menoufia Governorate in terms of disaster and preparedness.

\subsection{Aim of the study}

This study aim to evaluate the effect of guidance booklet on knowledge and attitude about disaster preparedness among nurses through:

(1) Assessing the knowledge of nurses regarding disasters and hospital disasters preparedness

(2) Assessing attitudes of nurses towards disaster management

(3) Developing guidance booklet of hospital disaster according nurses' needs.

(4) Evaluating the effect of guidance booklet on the nurses.

\subsection{Research hypotheses}

- H1: Nurses have limited knowledge and negative attitude regarding hospital disasters preparedness

- H2: There will be significant differences between the results of the pre-post booklet tests as regards knowledge and attitude of nurses in relation to disasters preparedness.

\section{METHOD}

\subsection{Research design}

A quasi experimental design with pre- post- follow up assessment was used to conduct the study.

\subsection{Study variables}

- Dependent variable: Knowledge and attitude regarding disaster preparedness

Published by Sciedu Press
- Independent variable: Structured guidance booklet regarding disaster preparedness

\subsection{Setting}

The study was conducted in University Hospital, in Menoufia Governorate, Egypt. This hospital is divided into four buildings; Main, Specialty, Emergency, and Oncology.

\subsection{Subjects}

Convenience sample was taken from the aforementioned hospital buildings. It consisted of all nursing managers (nursing directors and nursing supervisors $n=12$ ), and all head nurses $(n=48)$ and a proportional allocation sample of $30 \%$ from staff nurses $(n=280)$, available at the time of the study. Their total number was 340 nurses. They have all fulfilled the eligibility criterion of a working experience of not less than one year of the study settings.

\subsection{Tools for data collection}

Two different tools were used in the present study for data collection.

Tool one: An interview questionnaire sheet was developed by the researchers based on relevant literature includes three parts:

Part I: This part includes socio demographic data such as age, occupation, qualification, department, experience years, source of information about disaster and attendance training courses.

Part II: Knowledge disasters questionnaire. It was adapted from Moabi. ${ }^{[22]}$ It was designed to assess nurses' knowledge regarding disaster: general disaster, whether nurses knew what a disaster is, classification, principal causes of disasters, what a disaster plan is, and disaster plan phases, whether they knew where to find the plan. It included 37 questions and were divided into five subgroups: 1-Concept of terminology (12Q), 2-Types and classification (13Q), 3-Pre disaster risk reduction (3Q), 4-Post disaster recovery management (3Q), and 5-Characteristics of a disaster plan (6Q). Scoring system: each question was granted one point for the correct answer, and zero for the wrong one. The total score for all questions was 37. Total scores were expressed as percentages. If the score was less than $60 \%$, it was considered poor level of knowledge, and from $60 \%$ to $75 \%$ it was considered moderate level of knowledge, and more than $75 \%$ it was considered good level of knowledge.

Part III: Hospital disasters preparedness questionnaire. It was designed to assess nurses' awareness by hospital disasters preparedness on external or internal level. It was adapted from IFRC, ${ }^{[23]}$ Mostafa $^{[24]}$ and Abd Elazeem et al. ${ }^{[25]}$ It 
consisted two categories: i) Questionnaires related to external disasters preparedness included 42 questions and were divided into three subgroups, written hospital disaster plan preparedness, response and recovery plan, Nursing role in external disaster and their function during disaster, and training and education to control disaster. ii) Internal disaster preparedness questionnaires included 54 questions and were divided into five subgroups: hospital preparedness for safety measures component environment, hospital preparedness for adequacy supplies and equipment required in a disaster, hospital prevention measures for fire and explosions, hospital prevention precautions for infection control, and hospital evacuation plan. Scoring system: each question was granted one point for the "yes" answer, and zero for the "no" answer. The total score for all questions was 96. Total scores were expressed as percentages. The nurse was considered "satisfactory awareness" if percent score was $60 \%$ or more, and "unsatisfactory awareness" regarding hospital disasters preparedness if less than $60 \%$.

Tool Two: Attitudes scale. It was designed to assess attitudes of nurses towards disaster management plan. It was developed by Moabi. ${ }^{[22]}$ The scale was translated into Arabic and modified by the researchers. It consisted of 12 statements with possible responses: "agree", "not sure" and "disagree" were scored "2", "1" and " 0 ", respectively, for positive items. The scoring was reversed in case of negative items. All scores were expressed as percentages. The Attitude was considered positive attitude if the percent score was $60 \%$ or more and negative attitude if less than $60 \%$.

\subsection{Validity and reliability of the instrumentation}

\subsubsection{Validity}

Tools of data collection were translated into Arabic and reviewed for their content validity by five experts was selected to test the content and face validity of the instruments. The panel included two experts from nursing administration department, two experts from Medical Surgical Nursing departments and one Community Health Nursing departments (Menoufia University).

\subsubsection{Reliability}

The tools were tested for reliability by test-retest technique by 10 nurses from four hospital buildings: Main, Specialty, Emergency, and Oncology hospitals. Who were interviewed twice at an interval of one week period and data was analyzed and compared. The reliability was assessed in a pilot study by measuring their internal consistency using Cronbach's alpha coefficient method. This turned to be $(\alpha=0.92)$ for first tool; $(\alpha=0.97)$ for attitude tool. Thus indicates a high degree of reliability for the study tools.

\subsection{Pilot study}

A pilot study was carried out with 20 nurses who not included in the present study. It was done to test the clarity and applicability of the study tools. The necessary modification was done. The average time needed to complete the questionnaires (I) ranged between (15-20 minutes), and questionnaire (II) ranged between (5-15 minutes).

\subsection{Field work}

- An official letter clarifying the purpose of the study was obtained letters from the faculty of nursing clarifying the aim of the study to the hospital's director to conduct the study and collect the necessary data.

- Data was collected upon seven month started from first of February 2014 until the end of August 2014.

- The researchers met with nurses, explained to them the purpose of the study, and asked for their oral consent to participate. Those who agreed to participate were given the tool and asked to fill it out and return it anonymously in the same setting or at most the next day. The researchers were available for any clarifications.

- The guidance booklet was developed by the researchers based on the needed knowledge that can help nurses improving their awareness regarding disaster preparedness.

- Also she scheduled with them the teaching sessions and the nurses were divided into groups according to buildings of hospital, each group contains 9 to 10 nurses.

- The information guidance booklet has been implemented for nurses in terms of sessions and teaching during their official working hours. There were a total of 34 sessions, at a rate of four to five times per week. Number of nurses in each session ranged between 9-10 nurses. Each nurse obtained a copy of the information guidance booklet that included all the learning contents.

\subsection{Ethical consecrations}

All the relevant principles of ethics in research were followed. The study was approved by the pertinent authority. Participants' consent to participate was obtained after informing them about their rights to participate, refuse, or withdraw at any time without any harmful effect during or after sessions. Total confidentiality of any obtained information was ensured. The study maneuver could not entail any harmful effects on participants. 


\subsection{Data collection}

Data collection lasted from the first of February 2014 until the end of August 2014. The researcher collects the data by using knowledge questionnaire awareness questionnaire and attitude scale questionnaire and conduct guidance information booklet on disaster preparedness after that post test will be conducted with same questionnaire to evaluate the effectiveness of guidance booklet.

\subsection{Statistical analysis}

Statistical analysis: Analysis was performed using SPSS, version 16.0. Proportions were used for categorical variables. Mean, percentage and standard deviation will be used to assess the pre test, post test and follow test scores. Paired' test will be used to compare the pre test, post test and follow test scores. Spearman correlation was used to show the relation between quantitative and ordinal variables. Pearson correlation between quantitative variables was applied. $P<.05$ was considered significant.

\section{RESULT}

Table 1 shows the characteristics of the studied nurses, the majority of nurses $(47.6 \%)$ their age ranged from $20-29$ years and $(47.1 \%)$ of them had diploma of nursing. Also, about $(39.4 \%)$ of them had below 5 years of experience. Also the majority of nurses $(82.4 \%)$ were staff nurses, working at specialty hospital setting $(34.1 \%)$. As regard to previously of attended training for the study sample, it was found that, the majority of nurses $(88.8 \%)$ had no chance to attend training courses about the study topic, and obtained information on disasters through different mass media and the most source of information about disaster was T.V (36.2\%).

Table 1. Socio demographic characteristics of studied group $(\mathrm{N}=340)$

\begin{tabular}{|c|c|c|}
\hline Socio demographic characteristics & No. & $\%$ \\
\hline \multicolumn{3}{|l|}{ Age/years: } \\
\hline$<20$ & 35 & 10.3 \\
\hline $20-29$ & 162 & 47.6 \\
\hline $30-39$ & 102 & 30 \\
\hline$\geq 40$ & 41 & 12.1 \\
\hline$\overline{\mathbf{X}} \pm \mathrm{SD}$ & $30.2 \pm 6.92$ & \\
\hline Range & $17-40$ & \\
\hline \multicolumn{3}{|l|}{ Qualification: } \\
\hline Diploma & 160 & 47.1 \\
\hline Technical institute & 62 & 18.2 \\
\hline Bachelor & 108 & 31.8 \\
\hline Bachelor + diploma & 7 & 2.1 \\
\hline Master & 3 & 0.9 \\
\hline \multicolumn{3}{|l|}{ Occupation: } \\
\hline Staff nurses & 280 & 82.4 \\
\hline Head nurse & 48 & 14.1 \\
\hline Nurse manager & 12 & 3.6 \\
\hline \multicolumn{3}{|l|}{ Years of experience: } \\
\hline$<5$ & 134 & 39.4 \\
\hline $5-10$ & 113 & 33.2 \\
\hline$\geq 10$ & 93 & 27.4 \\
\hline$\overline{\mathbf{X}} \pm \mathrm{SD}$ & $7.27 \pm 4.48$ & \\
\hline Range & $2-16$ & \\
\hline \multicolumn{3}{|l|}{ Attending of training courses: } \\
\hline Yes & 38 & 11.2 \\
\hline No & 302 & 88.8 \\
\hline
\end{tabular}

Figure 1 clarifies the majority of the studied nurses had poor level of knowledge $(75 \%)$ regarding disaster and disaster preparedness, had unawareness about hospital disasters preparedness $(87.4 \%)$, and negative attitude towards disaster management $(62.5 \%)$.

Figure 2 illustrates the distribution of nurses according to buildings of hospital. The majority of the nurses working as staff nurses at specialty hospital setting (34.1\%).

Figure 3 illustrates source of information about disaster among nurses that obtained information on disasters through different mass media. $36.2 \%$ of the participants regarded TV as the most appropriate means of media communication to 
prepare nurses for disaster.

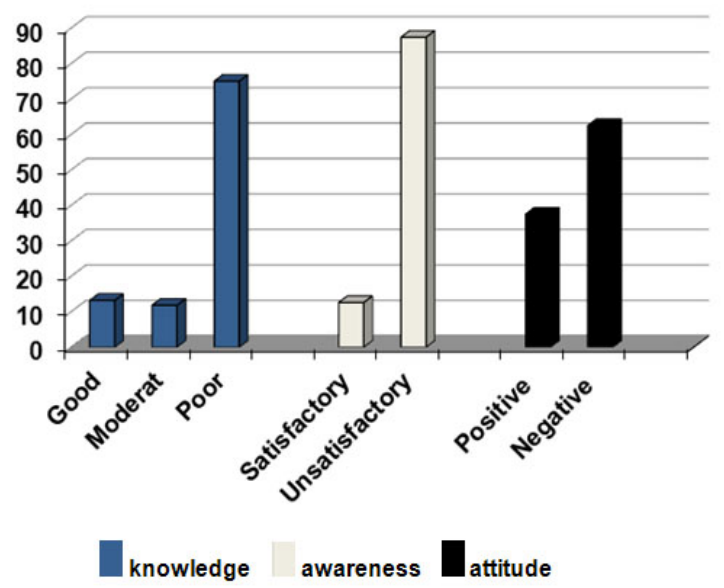

Figure 1. Pre-test knowledge, awareness, and attitude regarding disaster and hospital disaster preparedness among nurses in the study sample $(\mathrm{n}=340)$

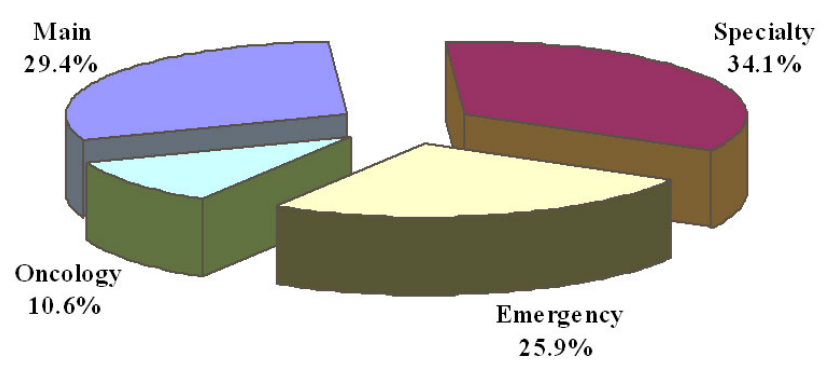

Figure 2. Distribution of nurses according to buildings of hospital $(\mathrm{n}=340)$

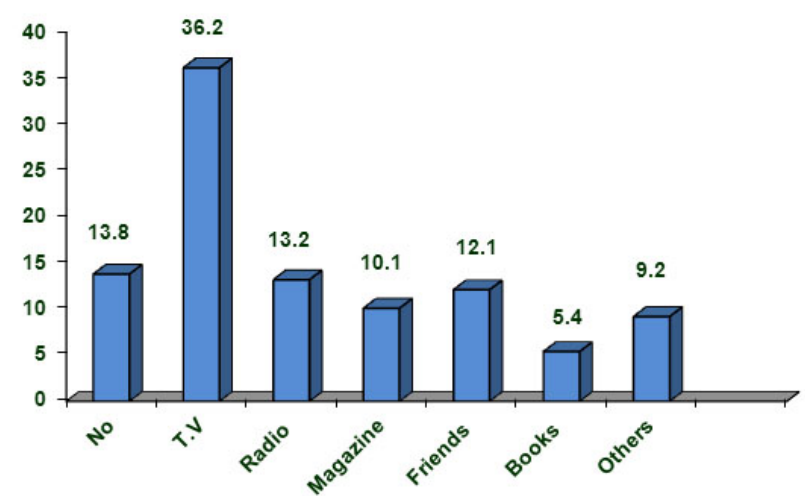

Figure 3. Source of information about disaster among nurses in the study sample $(\mathrm{n}=340)$

Table 2 shows there was a significant difference between the mean pre test score and the mean post test score and between the mean follow test score on knowledge among nurses regarding disaster. The baseline mean scores for total and subtotal knowledge are low before guidance booklet (19.6 \pm 6.34 ). However, an improvement in the mean knowledge scores after the application of the guidance booklet $(30.3 \pm$ 3.8 ), and a slight decline mean knowledge scores after three months compared to the post-test $(29.2 \pm 4.2)$.

As shown in Table 3, there was a statistical significant differences among the studied nurses about awareness regarding internal and external disaster plan where $p 1<.001$ between pre and post test and $p 2<.001$ between pre and follow up test. Mean of total awareness of the studied group at post test is higher than mean of total awareness at pre test.

Table 2. Comparison of knowledge of nurses regarding disaster and disaster preparedness (pre test, post test and follow up) $(\mathrm{N}=340)$

\begin{tabular}{|c|c|c|c|c|c|}
\hline \multirow{3}{*}{ Knowledge } & \multicolumn{3}{|c|}{ Studied group } & \multirow{3}{*}{$\begin{array}{c}\text { paired } \\
t \text {-test }\end{array}$} & \multirow{3}{*}{$P$ value } \\
\hline & Pre-test & Post test & Follow up test & & \\
\hline & $\overline{\mathbf{X}} \pm \mathbf{S D}$ & $\overline{\mathbf{X}} \pm \mathrm{SD}$ & $\overline{\mathbf{X}} \pm \mathrm{SD}$ & & \\
\hline \multirow{2}{*}{ - Concept of terminology (12Q) } & \multirow{2}{*}{$8.6 \pm 1.77$} & \multirow{2}{*}{$10.9 \pm 0.64$} & \multirow{2}{*}{$10.7 \pm 1.02$} & 31.2 & $P 1:<.001$ \\
\hline & & & & 29.6 & $P 2:<.001$ \\
\hline \multirow{2}{*}{ - Types and classification (13Q) } & \multirow{2}{*}{$7.68 \pm 2.10$} & \multirow{2}{*}{$10.8 \pm 1.18$} & \multirow{2}{*}{$10.4 \pm 1.31$} & 44.4 & $P 1:<.001$ \\
\hline & & & & 31.4 & $P 2:<.001$ \\
\hline \multirow{2}{*}{ - Pre disaster risk reduction (3Q) } & \multirow{2}{*}{$1.11 \pm 0.87$} & \multirow{2}{*}{$2.5 \pm 0.52$} & \multirow{2}{*}{$2.5 \pm 0.56$} & *15.6 & $P 1:<.001$ \\
\hline & & & & 15.5 & $P 2:<.001$ \\
\hline \multirow{2}{*}{$\begin{array}{l}\text { - Post disaster recovery management } \\
\text { (3Q) }\end{array}$} & \multirow{2}{*}{$0.89 \pm 0.80$} & \multirow{2}{*}{$2.30 \pm 0.60$} & \multirow{2}{*}{$2.29 \pm 0.61$} & $* 16.1$ & $P 1:<.001$ \\
\hline & & & & 16 & $P 2:<.001$ \\
\hline \multirow{2}{*}{ - Preparedness plan (6Q) } & \multirow{2}{*}{$1.36 \pm 1.35$} & \multirow{2}{*}{$3.70 \pm 1.38$} & \multirow{2}{*}{$3.36 \pm 1.4$} & $* 15.9$ & $P 1:<.001$ \\
\hline & & & & 15.5 & $P 2:<.001$ \\
\hline \multirow{2}{*}{ Total score (37) } & \multirow{2}{*}{$19.6 \pm 6.34$} & \multirow{2}{*}{$30.3 \pm 3.8$} & \multirow{2}{*}{$29.2 \pm 4.2$} & 60.1 & $P 1:<.001$ \\
\hline & & & & 49.3 & $P 2:<.001$ \\
\hline
\end{tabular}

*Wilcoxon test; $P 1$ : between pre and post test; $P 2$ : between pre and follow up test. 
Table 3. Comparison of awareness of nurses regarding hospital disasters (pre test, post test and follow up) $(\mathrm{N}=340)$

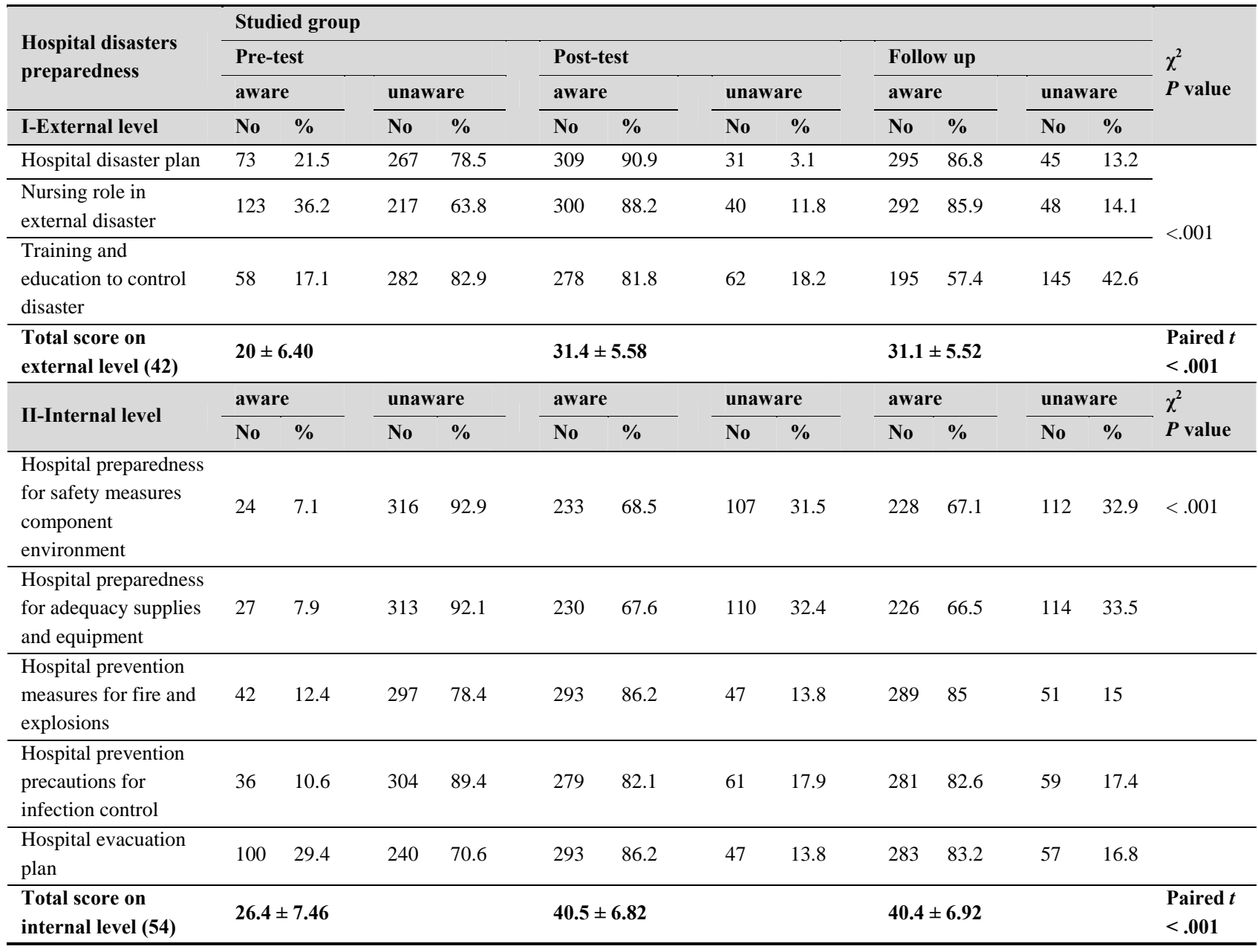

Table 4 shows the majority of the studied nurses disagree about some positive items of attitude toward disaster management at pre test measurement and agree at post and follow up test measurement. There was a statistical significant differences among the studied nurses about attitude toward disaster management at pre test, post test and follow up where $p<$ .001 .

Table 5 illustrated the majority of the studied nurse had poor of total knowledge (75\%), unsatisfactory awareness $(87.4 \%)$ and had negative attitude $(62.5 \%)$ toward regarding disaster and hospital disaster preparedness at pre test measurement time. There was a statistical significance differences among the studied nurses regarding knowledge, awareness, and attitude regarding disaster and hospital disaster preparedness at pre- post and follow up test.

As displayed from Table 6, that the highest percentages of nurses who had poor knowledge had negative attitude. Conversely, the highest percentages of nurses who had good knowledge had positive attitude. These differences were ob- served at the pre-, post, and follow-up phases of the booklet. They were all statistically significant, $p<.001$.

Table 7 illustrated the relation between nurses' awareness and their attitude towards disasters turned to be statistically significant at various phases of the booklet $(p<.001)$. It is evident that almost all nurses who had negative attitude had unsatisfactory awareness at the pre (100\%), post (45.9.0\%), and follow-up (37.5\%) phases. Conversely, the highest percentage of nurses who had positive attitude had satisfactory awareness at the pre-, post-, and follow-up phases (33.6\%, $96.4 \%$, and $96.5 \%$, respectively). They were all statistically significant, $p<.001$.

Table 8 shows Partial correlation coefficients, adjusted for the effect of booklet, were computed among nurses' knowledge, attitude and awareness e scores related to disasters. As shown in table statistically significant strong positive correlations were found between each two of these three parameters, $p<.001$. 
Table 4. Comparison of attitude of nurse toward disaster management (pre test, post test and follow up) $(\mathrm{N}=340)$

\begin{tabular}{|c|c|c|c|c|c|c|c|}
\hline \multirow{3}{*}{ Attitude } & \multicolumn{6}{|c|}{ Studied group } & \multirow{3}{*}{$\begin{array}{l}\chi^{2} \text { test } \\
P \text { value }\end{array}$} \\
\hline & \multicolumn{2}{|c|}{ Pre test } & \multicolumn{2}{|c|}{ Post test } & \multicolumn{2}{|c|}{ Follow up } & \\
\hline & No. & $\%$ & No. & $\%$ & No. & $\%$ & \\
\hline \multicolumn{8}{|c|}{ Positive items } \\
\hline \multicolumn{8}{|c|}{$\begin{array}{l}\text { Management should be adequately prepared before } \\
\text { disaster occur }\end{array}$} \\
\hline Agree & 135 & 39.7 & 294 & 86.5 & 308 & 90.6 & $<.001$ \\
\hline Not sure & 117 & 34.4 & 14 & 4.1 & 15 & 4.4 & \\
\hline Disagree & 88 & 25.9 & 32 & 9.4 & 17 & 5.0 & \\
\hline \multicolumn{8}{|c|}{$\begin{array}{l}\text { Potential hazards likely to cause disasters should be } \\
\text { identified and deal with }\end{array}$} \\
\hline Agree & 152 & 44.7 & 294 & 86.5 & 298 & 87.6 & $<.001$ \\
\hline Not sure & 114 & 33.5 & 7 & 2.1 & 18 & 5.3 & \\
\hline Disagree & 74 & 21.8 & 39 & 11.4 & 24 & 7.1 & \\
\hline \multicolumn{8}{|c|}{ Training is necessary for all health manager } \\
\hline Agree & 119 & 35.0 & 271 & 79.7 & 273 & 80.3 & \multirow{3}{*}{$<.001$} \\
\hline Not sure & 121 & 35.6 & 58 & 17.1 & 51 & 15.0 & \\
\hline Disagree & 100 & 29.4 & 11 & 3.2 & 16 & 4.7 & \\
\hline \multicolumn{8}{|c|}{ Do you think it is necessary to have disaster plan } \\
\hline Agree & 153 & 45.0 & 209 & 90.9 & 309 & 90.8 & \multirow{3}{*}{$<.001$} \\
\hline Not sure & 96 & 28.2 & 25 & 7.4 & 25 & 7.4 & \\
\hline Disagree & 91 & 26.8 & 6 & 1.7 & 6 & 1.8 & \\
\hline \multicolumn{8}{|c|}{ Disaster plan needs to regularly update } \\
\hline Agree & 160 & 47.1 & 209 & 90.9 & 325 & 95.6 & \multirow{3}{*}{$<.001$} \\
\hline Not sure & 12 & 3.5 & 25 & 7.4 & 1 & 0.3 & \\
\hline Disagree & 168 & 49.4 & 6 & 1.7 & 14 & 4.1 & \\
\hline \multicolumn{8}{|c|}{ Disaster simulation should occur frequently in hospital } \\
\hline Agree & 104 & 30.6 & 322 & 94.7 & 280 & 82.3 & \multirow{3}{*}{$<.001$} \\
\hline Not sure & 116 & 34.1 & 0 & 0.0 & 35 & 10.3 & \\
\hline Disagree & 120 & 35.3 & 18 & 5.3 & 25 & 7.4 & \\
\hline \multicolumn{8}{|c|}{ Drills should be conducted in the hospital } \\
\hline Agree & 127 & 37.4 & 273 & 80.3 & 265 & 77.9 & \multirow{3}{*}{$<.001$} \\
\hline Not sure & 62 & 18.2 & 19 & 5.6 & 36 & 10.6 & \\
\hline Disagree & 151 & 44.4 & 48 & 14.1 & 39 & 11.5 & \\
\hline Negative ite & & & & & & & \\
\hline I don't neec & & & & & & & \\
\hline Agree & 190 & 55.9 & 61 & 17.9 & 45 & 13.2 & \\
\hline Not sure & 50 & 14.7 & 38 & 11.2 & 51 & 15.0 & .001 \\
\hline Disagree & 100 & 29.4 & 241 & 70.9 & 244 & 71.8 & \\
\hline I don't pre & & & & & & & \\
\hline Agree & 271 & 79.7 & 153 & 45.0 & 186 & 54.7 & \\
\hline Not sure & 58 & 17.1 & 96 & 28.2 & 143 & 42.1 & $<.001$ \\
\hline Disagree & 11 & 3.2 & 91 & 26.8 & 11 & 3.2 & \\
\hline Disaster pla & & & & & & & \\
\hline Agree & 143 & 42.1 & 0 & 0.0 & 26 & 7.6 & $<.001$ \\
\hline Not sure & 119 & 35.0 & 26 & 7.6 & 24 & 7.1 & $<.001$ \\
\hline Disagree & 78 & 22.9 & 314 & 92.4 & 290 & 85.3 & \\
\hline Disaster ar & & & & & & & \\
\hline Agree & 153 & 45.0 & 186 & 54.7 & 186 & 54.7 & \\
\hline Not sure & 97 & 28.5 & 143 & 42.1 & 145 & 42.6 & . 001 \\
\hline Disagree & 90 & 26.5 & 11 & 3.2 & 9 & 2.6 & \\
\hline Disaster ma & & & & & & & \\
\hline Agree & 75 & 22.0 & 100 & 29.4 & 53 & 15.6 & \\
\hline Not sure & 141 & 41.5 & 6 & 1.8 & 10 & 2.9 & $<.001$ \\
\hline Disagree & 124 & 36.5 & 234 & 68.8 & 277 & 81.5 & \\
\hline
\end{tabular}


Table 5. Nurses' knowledge, awareness, and attitude regarding disaster and hospital disaster preparedness at pre- post and follow up test

\begin{tabular}{|c|c|c|c|c|c|c|c|}
\hline \multirow{3}{*}{ Items } & \multicolumn{6}{|c|}{ Studied group $(\mathrm{n}=\mathbf{3 4 0})$} & \multirow{3}{*}{$\begin{array}{l}\chi^{2} \text { test } \\
\text { (p-value) }\end{array}$} \\
\hline & \multicolumn{2}{|l|}{ Pre } & \multicolumn{2}{|l|}{ Post } & \multicolumn{2}{|c|}{ Follow-up } & \\
\hline & No. & $\%$ & No. & $\%$ & No. & $\%$ & \\
\hline \multicolumn{8}{|l|}{ Total knowledge: } \\
\hline Poor level (<60\%) & 255 & 75 & 17 & 5 & 37 & 10.9 & \multirow{3}{*}{$<.001 *$} \\
\hline Moderate level (60\%-75\%) & 40 & 11.8 & 69 & 20.3 & 54 & 15.9 & \\
\hline Good level (> 75\%) & 45 & 13.2 & 254 & 74.7 & 249 & 73.2 & \\
\hline \multicolumn{8}{|l|}{ Total awareness: } \\
\hline Satisfactory $(\geq 60 \%)$ & 43 & 12.6 & 312 & 91.8 & 309 & 90.9 & \multirow[t]{2}{*}{$<.001^{*}$} \\
\hline Unsatisfactory $(<60 \%)$ & 297 & 87.4 & 28 & 8.2 & 31 & 9.1 & \\
\hline \multicolumn{7}{|l|}{ External disaster: } & \multirow[t]{3}{*}{$<.001 *$} \\
\hline Satisfactory $(\geq 60 \%)$ & 40 & 11.7 & 302 & 88.8 & 295 & 86.8 & \\
\hline Unsatisfactory $(<60 \%)$ & 300 & 88.3 & 38 & 11.2 & 45 & 13.2 & \\
\hline \multicolumn{8}{|l|}{ Internal disaster: } \\
\hline Satisfactory $(\geq 60 \%)$ & 37 & 10.9 & 311 & 91.5 & 292 & 85.9 & \multirow[t]{2}{*}{$<.001^{*}$} \\
\hline Unsatisfactory $(<60 \%)$ & 303 & 89.1 & 29 & 8.5 & 48 & 14.1 & \\
\hline \multicolumn{8}{|l|}{ Total attitude: } \\
\hline Positive ( $\geq 60 \%$ ) & 128 & 37.5 & 303 & 89.1 & 284 & 83.5 & \multirow{2}{*}{$<.001$} \\
\hline Negative $(<60 \%)$ & 212 & 62.5 & 37 & 10.9 & 56 & 16.5 & \\
\hline
\end{tabular}

$(*)$ statistically significant at $p<.05$

Table 6. Relation between knowledge related to disaster among nurses in the study sample and their attitude and awareness throughout booklet phases

\begin{tabular}{|c|c|c|c|c|c|c|c|c|}
\hline \multirow{3}{*}{ Items } & \multicolumn{6}{|c|}{ Knowledge } & \multirow{3}{*}{$\chi^{2}$} & \multirow{3}{*}{$P$ value } \\
\hline & \multicolumn{2}{|c|}{ Good } & \multicolumn{2}{|c|}{ Moderate } & \multicolumn{2}{|c|}{ Poor } & & \\
\hline & No. & $\%$ & No. & $\%$ & No. & $\%$ & & \\
\hline \multicolumn{9}{|l|}{ Pre: } \\
\hline \multicolumn{9}{|l|}{ Attitude: } \\
\hline +ve & 38 & & 32 & 80.0 & 58 & 22.7 & \multirow{3}{*}{31.9} & \multirow{2}{*}{$<.001^{*}$} \\
\hline -ve & 7 & 84.4 & 8 & 20.0 & 197 & 77.3 & & \\
\hline \multicolumn{8}{|l|}{ Awareness: } & \\
\hline Satisfactory & 5 & \multirow{2}{*}{11.188 .9} & 32 & 80.0 & 6 & 2.4 & \multirow{2}{*}{9.19} & \multirow{2}{*}{$<.05 *$} \\
\hline Unsatisfactory & 40 & & 8 & 20.0 & 249 & 97.6 & & \\
\hline \multicolumn{9}{|l|}{ Post: } \\
\hline \multicolumn{9}{|l|}{ Attitude: } \\
\hline +ve & 233 & 91.7 & 56 & 81.2 & 13 & 76.5 & \multirow{2}{*}{9.19} & \multirow{2}{*}{$<.05^{*}$} \\
\hline -ve & 21 & 8.3 & 13 & 18.8 & 4 & 23.5 & & \\
\hline \multicolumn{9}{|l|}{ Awareness: } \\
\hline Satisfactory & 241 & 94.9 & 56 & 81.2 & 15 & 88.2 & \multirow{2}{*}{13.8} & \multirow{2}{*}{$<.001 *$} \\
\hline Unsatisfactory & 13 & 5.1 & 13 & 18.8 & 2 & 11.8 & & \\
\hline \multicolumn{9}{|l|}{ Follow up: } \\
\hline \multicolumn{9}{|l|}{ Attitude: } \\
\hline +ve & 243 & 97.6 & 51 & 94.4 & 9 & 24.3 & \multirow{2}{*}{20.3} & \multirow{2}{*}{$<.001 *$} \\
\hline -ve & 6 & 2.4 & 3 & 5.6 & 28 & 75.7 & & \\
\hline \multicolumn{9}{|l|}{ Awareness: } \\
\hline Satisfactory & 237 & 95.2 & 41 & 75.9 & 34 & 91.9 & \multirow{2}{*}{27.8} & \multirow{2}{*}{$<.001^{*}$} \\
\hline Unsatisfactory & 12 & 4.8 & 13 & 24.1 & 3 & 8.1 & & \\
\hline
\end{tabular}

$\left.{ }^{*}\right)$ statistically significant at $p<.05$ 
Table 7. Relation between awareness related to hospital disasters among studied nurses and their attitude throughout booklet phases

\begin{tabular}{|c|c|c|c|c|c|c|}
\hline \multirow{3}{*}{ Awareness to hospital disasters } & \multicolumn{4}{|c|}{ Attitude } & \multirow{3}{*}{ Fisher's Exact test } & \multirow{3}{*}{$p$-value } \\
\hline & \multicolumn{2}{|l|}{$+\mathrm{Ve}$} & \multicolumn{2}{|l|}{$-\mathrm{Ve}$} & & \\
\hline & No. & $\%$ & No. & $\%$ & & \\
\hline \multicolumn{7}{|l|}{ Pre } \\
\hline Satisfactory & 43 & 33.6 & 0 & 0 & 6.01 & $<.001^{*}$ \\
\hline Un Satisfactory & 85 & 66.4 & 212 & 100 & & \\
\hline \multicolumn{7}{|l|}{ Post } \\
\hline Satisfactory & 292 & 96.4 & 20 & 54.1 & 78.1 & $<.001^{*}$ \\
\hline Un Satisfactory & 11 & 3.6 & 17 & 45.9 & & \\
\hline \multicolumn{7}{|l|}{ Follow up } \\
\hline Satisfactory & 274 & 96.5 & 35 & 62.5 & 78.4 & $<.001^{*}$ \\
\hline Un Satisfactory & 10 & 3.5 & 21 & 37.5 & & \\
\hline
\end{tabular}

$\left.{ }^{*}\right)$ statistically significant at $p<.05$

Table 8. Partial correlation matrix of nurses' knowledge, attitude, and awareness related to disaster adjusted for the effect of booklet

\begin{tabular}{llllll}
\hline \multirow{2}{*}{ Variable } & \multicolumn{2}{l}{ Knowledge } & & \multicolumn{2}{c}{ Awareness } \\
\cline { 2 - 3 } & $\boldsymbol{r}$ & $\boldsymbol{p}$ & & $\boldsymbol{p}$ & $\boldsymbol{p}$ \\
\hline Knowledge & & & & \\
Awareness & 0.91 & $<.001$ & & \\
Attitude & 0.47 & $<.001$ & & 0.54 & $<.001$ \\
\hline
\end{tabular}

$(*)$ statistically significant at $p<.05$

\section{Discussion}

Disasters are unpredictable events that kill and affect people, demolish properties and disrupt environment. Nurses, as the largest group of committed health personnel, often working in difficult situations with limited resources, play vital roles in dealing with the victims and when disasters strike, serving as the first responders, triage officers and care providers, coordinators of care and services, providers of information or education, and counselors. However, health systems and health care delivery in disaster situations are only successful when nurses have the fundamental disaster competencies or abilities to rapidly and effectively respond. The present study included 340 nurses; their mean age was $(30.2 \pm 6.92)$ years. The majority of the nurses their age ranged from 20-29 years, and working as staff nurses at specialty hospital setting, as regard the educational level; the majority of the nurses had diploma of nursing, their experiences below 5 years, and difficult chance to attend training courses about the disasters, and obtained information on disasters through different mass media. Jahangiri et al. ${ }^{[26]}$ shown that Over $70 \%$ of the participants $(71.7 \%)$ reported TV as the most appropriate means of media communication to prepare people for an earthquake disaster.
According to the present study findings, assessment of nurses' knowledge about disasters has revealed high deficiency. This means that high majority of nurses had low level of knowledge in the pre-intervention phase. In the same line Ibrahim and El Hosany ${ }^{[27]}$ revealed that about one fifth of nurses had satisfactory knowledge related to classifications of disasters. Additionally, the finding of the present study is in agreement with Sinha et al. ${ }^{[28]}$ showed that undergraduate medical students have little knowledge about disasters. On the other hand, the great majority of the study subjects had never attended previous training courses related to this subject. They concentrate in their work rather than to update their knowledge or continue their education. In the same line Chimenya ${ }^{[20]}$ revealed that hospital was found to have weaknesses in terms of training and education of their workers.

Regarding knowledge about disasters among studied nurses through the post-intervention and follow-up phases, the present study findings have revealed statistical significant improvement after application of the guidance booklet. This was noticed both at the post-test and follow-up phases, compared to pre-test; before application of booklet. The results is in agreement with Samantha et al. ${ }^{[29]}$ shown that there was a significant difference between pre test and post test on knowledge constituting disaster nursing competencies among students. Zhang et al. ${ }^{[30]}$ found that $32 \%$ of the hospital nurses know disaster nursing knowledge before training, and $51.7 \%$ of them know it after training; $41.5 \%$ of the hospital nurses know disaster nursing operation before training, and $58.9 \%$ of them know it after training $(P<.01)$, and also concluded that nurses was lack of disaster nursing perceptive, and after training, the situation was improved greatly. In the same line Hokrani bhimanna ${ }^{[31]}$ who has also shown that there was a significant difference between the mean pre test score and the mean post test score on knowledge among 
students regarding disaster preparedness. Moreover, these satisfactory results obtained after the guidance booklet implementation are in agreement with the results of Mangala and Ahirrao ${ }^{[32]}$ who concluded that the information booklet improved knowledge of people regarding disaster preparedness. In the same line Ahayalimudin et al. ${ }^{[33]}$ revealed that nurses who attended disaster-related education or training are more likely to have adequate knowledge.

According to the present study findings, assessment of nurses' awareness by hospital disasters preparedness on external and internal levels has revealed high deficiency. This means that high majority of nurses had unsatisfactory level of awareness in the pre-intervention phase. In the same line Ibrahim and El Hosany ${ }^{[27]}$ showed that nurses have very low percentage recorded for their awareness about hospital internal and external disaster preparedness. In the same line Abd Elazeem et $a l .{ }^{[25]}$ revealed that the majority the study subjects had low awareness about all components of the disaster plan preparedness. Also, Olivia et al. ${ }^{[34]}$ concluded that nurses in Hong Kong are not adequately prepared for disasters. From the researcher point of view this lack of awareness about the hospital disaster preparedness plan, and all items that related to the lack in the required knowledge lead to inability to management disasters in hospitals. Yang et al. ${ }^{[35]}$ found that nurses were inadequate and ill prepared for disasters. Also, Al Khalaileh et al. ${ }^{[36]}$ reported that registered nurses considered themselves weak to moderate in terms of their level of awareness of preparedness for disaster management. Chimenya ${ }^{[20]}$ found that high proportion of workers at the hospital who did not know about the plan, and who did not know what a hospital disaster plan should contain. Bagaria et al. ${ }^{[13]}$ reported that the hospital should always be prepared with written disaster plan that responds to external disasters to help in providing assistance to victims, the hospital is also vulnerable to disasters directly occurring within its walls; so preparation must be made in response to internal disasters, and the most common of all is fire.

Regarding awareness about hospital disasters among studied nurses through the post-intervention and follow-up phases, the present study findings have revealed statistical significant improvement after application of the guidance booklet. This was noticed both at the post-test and follow-up phases, compared to pre-test; before application of booklet. The results is in agreement with Collander et al. ${ }^{[37]}$ who showed that an increase in awareness of healthcare workers related to the principles of hospital disaster by participation in hospital disaster life support training course, and the average score on the pre-test was $69.1+/-12.8$ for all positions, and the post-test score was $89.5+/-6.7$, an improvement of 20.4 points $(p<.0001,17.2-23.5)$. As regards level of nurses'

Published by Sciedu Press awareness to their role in external disasters preparedness the current study revealed that about one-third of nurses were satisfactory awareness to their role during disaster response and disaster preparedness. The result is in agreement with Ibrahim and El Hosany ${ }^{[27]}$ showed that slightly less than one fourth of nurses were aware about their role in external disasters. Also, Loke and Fung ${ }^{[19]}$ indicated that nurses were not aware of their roles in preparing the community or the vulnerable population for disaster.

The present study findings have revealed statistical significant improvement after application of the guidance booklet regarding awareness of nurses for their roles. From the researcher point of view, this happened as a result of the subject's enthusiasm to gain more information about disasters and their role and clarify the roles in each stage of process of preparedness and disaster response. The nurses request to putting poster that includes clarification for roles in their units. These finding is supported by Campbell et al., ${ }^{[38]}$ who stressed that nursing roles and expectations must be defined in the disaster plan and in job descriptions containing performance standards specific to disaster response.

Regarding nurses' awareness to important of training and education courses to control disaster the current study revealed that high majority of nurses had unsatisfactory level of awareness in the pre-intervention phase and do not feel the importance of the necessity of training on drill and education courses the results is in agreement with Ibrahim and El Hosany ${ }^{[27]}$ reported that only $14.7 \%$ of the studied nurses aware about the importance of training to control disaster. $\mathrm{Al}$ Khalaileh et al. ${ }^{[36]}$ suggested that additional training through courses and facility drills would be beneficial in increasing nurses' level of preparedness. Also, Abd Elazeem et al. ${ }^{[25]}$ showed that lack of hospital preparedness related to hospital drills, and training. But after the application of the guidance booklet they felt these satisfactory results on increase their awareness; the present study findings have revealed statistical significant improvement.

Regarding nurses' awareness by hospital disasters preparedness on internal level through the post-intervention and follow-up phases, the present study findings have revealed statistical significant improvement after application of the guidance booklet. This was noticed both at the post-test and follow-up phases, compared to pre-test; before application of booklet. The result is in agreement with O'Sullivan et al. ${ }^{\text {[39] }}$ who recommended that more training and information were needed to enhance preparedness for frontline health care workers, and of important members of the response community. Therefore, the application of the guidance booklet in the present study turned to be effective in increasing the level 
of nurses' awareness about hospital disasters preparedness.

According to the present study findings, assessment of nurses' awareness by hospital disasters preparedness on internal levels revealed that the majority the study subjects had unsatisfactory level of awareness about all items of the hospital disasters preparedness. In the same line Ibrahim and El Hosany ${ }^{[27]}$ reported that nurses have very low percentage recorded for their awareness about hospital internal disaster preparedness. Chagutah ${ }^{[40]}$ shows that local mechanisms for communicating and raising public awareness of the consequent risks and appropriate risk reduction options remain weak Through the post-intervention and follow-up phases, the present study findings have revealed statistical significant improvement after application of the guidance booklet.

Regards level of nurses' awareness to hospital preparedness for safety measures for component environment. The present study revealed unsatisfactory levels of awareness for preparedness about all items. The result is in agreement with Abd Elazeem et al. ${ }^{[25]}$ and Ibrahim and El Hosany ${ }^{[27]}$ showed that minority of nurses has awareness with their hospital environment preparedness. The present study findings have revealed statistical significant improvement in postintervention and follow-up phases after application of the guidance booklet. The nurses focused on interest to know all safety measures for hospital environment during all phases of disaster preparedness and hospital's mitigation and preparedness. These finding is supported by Mohamed and Zakaria, ${ }^{[41]}$ who pointed to the needed attention to hospital environment to prevent accidents, reducing injuries and errors and increasing organizational function because the hospital environment is considered a dangerous place.

Regards level of nurses' awareness to hospital preparedness for adequacy supplies and equipment. The present study revealed unsatisfactory levels of awareness about all supplies and equipment in hospital. The result is in agreement with Abd Elazeem et al. ${ }^{[25]}$ and Ibrahim and El Hosany ${ }^{[27]}$ showed that slightly of nurses has awareness with their hospital supplies and equipments. The present study findings have revealed statistical significant improvement in postintervention and follow-up phases after application of the guidance booklet. The nurses had aware about medical supplies, water supply, gas supply, electricity power and enumerate inventory list of all equipments in hospital. Hick et $a l .{ }^{[42]}$ reported that the hospital demand of water for three days must be available in case of disaster by secure water tank. This water storage must be in a secure and safe place.

Regards level of nurses' awareness to hospital prevention measures for fire and explosions and precautions for infection control. The present study revealed unsatisfactory levels of awareness .The result is in agreement with Abd Elazeem et al. ${ }^{[25]}$ and Ibrahim and El Hosany ${ }^{[27]}$ showed that slightly of nurses has awareness of infection control team, and lesser percentage of nurses were aware by the rules of isolation of infectious cases. The present study findings have revealed statistical significant improvement in post-intervention and follow-up phases after application of the guidance booklet. The nurses had aware about infection control programs and component, infection control committee team and specialist, rules, precautions, technique for infectious case, safety precaution for fire, awareness with daily maintenance avoiding explosions in hospital. The result is in agreement with Rebmann et al. ${ }^{[43]}$ who recommended that more infection control training program which infection control professionals' role in disaster preparedness and response is essential, even in noninfectious disease emergencies.

Regards level of nurses' awareness to hospital evacuation plan. The present study revealed that the major of nurses have lack of awareness for hospital evacuation plan. The result is in agreement with Ibrahim and El Hosany ${ }^{[27]}$ found that slightly more than one fourth of nurses' evacuation process during internal were aware with components of disasters. The present study findings have revealed statistical significant improvement in post-intervention and follow-up phases after application of the guidance booklet. The result is supported with Kaji and Lewis ${ }^{[44]}$ who recommended that a proper plan that explain clearly how to evacuate people and things inside the hospital must be available and practiced regularly.

Concerning nurses' attitude towards disaster management plan, the present study has shown that, before booklet implementation, most nurses had negative attitude towards disaster management plan preparedness and only very few of them had positive attitude. This finding is congruent with Sinha et $a l .{ }^{[28]}$ who has similarly reported that undergraduate medical students have a poor attitude towards disaster preparedness and mitigation However, These findings are contradictory with Liu et al. ${ }^{[45]}$ showed that most nurses (97.97\%) showed positive attitudes towards disaster relief work, and Ahayalimudin et al. ${ }^{[33]}$ reported that nurses had positive attitude towards disaster management.

After implementation of the guidance booklet, the findings of the present study have revealed statistically significant improvements in nurses' attitude towards the disaster management plan. This was detected both in the post and follow-up phases of the program. Thus, the great majority of nurses had positive attitude towards disaster management plan. This improvement in nurses' attitudes after booklet implementation may be attributed to the increase in participants' knowledge, 
associated with the modification in their look at the subject of disaster preparedness and management. In agreement with these present study finding related to nurses' attitude. Goyal et al. ${ }^{[46]}$ and Safan ${ }^{[47]}$ have reported an improvement in attitude after Educational Booklet. Nonetheless, according to the present study findings, nurses' attitude has shown a slight decline at the follow-up test, compared to post-test. However, this decline was minimal. Thus, the percentages of nurses with positive attitude were still higher, compared to pre-test.

The present study has also examined the relation between nurses' knowledge related to disasters hospital preparedness plan and nurses' attitude and awareness throughout booklet phases. The findings have indicated that the highest percentage of nurses who had poor knowledge had negative attitude, while the highest percentage of nurses who had good knowledge had acceptable and positive attitude. This statistically significant relation between nurses' knowledge and their attitude was noticed at the pre-, post, and follow-up phases of booklet implementation. This was further confirmed by the statistically significant positive correlation between knowledge and attitude scores. The result is in agreement with Sinha et al. ${ }^{[28]}$ concluded that the knowledge, attitude and practices of the undergraduate medical students about disaster preparedness and mitigation are very poor. This knowledge and awareness can be improved through exposing the students in terms of orientation workshops and mock drills and similar practical exercises, which could develop an interest in the topic. These findings are in agreement with Jiang et al. ${ }^{[48]}$ demonstrated that a significant positive relationship between nurses' attitudes and knowledge and level of competence in nursing practice and indicate that strategies need to be developed for nurses to improve their knowledge, attitudes and practice Chimenya ${ }^{[20]}$ reported that despite the poor knowledge about the disaster plan, the healthcare workers had the right attitude towards hospital emergency and disaster preparedness. But Ahayalimudin et al. ${ }^{[33]}$ found that nurses had inadequate knowledge but portrayed positive attitude towards disaster management.

Also, as regards the relation between nurses' attitude and awareness scores, the highest percentage of nurses who had negative attitude regarding disasters management plan had unsatisfactory awareness, and the relation was statistically significant. Conversely, the highest percentage of nurse who had positive attitude regarding disasters management plan had satisfactory awareness. This was also confirmed by the statistically significant positive correlation between attitude and total awareness scores.

Similar findings were also revealed as regards the relation between nurses' knowledge and total awareness scores. Higher percentage of nurses who had poor knowledge had unsatisfactory awareness, and higher percentages of nurses who had good knowledge had satisfactory awareness, and the relation was statistically significant. Moreover, knowledge and awareness scores were strongly and positively correlated. In the same line Lai et al. ${ }^{[49]}$ found that disaster nursing protocols provide healthcare knowledge essential to increase disaster awareness, preparation, response, and rehabilitation.

\section{Conclusion}

This study concluded that that guidance booklet was successful in achieving significant improvement in nurses' knowledge and awareness regarding disaster preparedness which was reflected in improvement and changing their attitude towards disaster management plan. The study has also indicated statistically significant strong positive correlations among nurses' knowledge, attitude, and awareness scores related to disaster preparedness.

\section{Recommendations}

(1) Training programs are essential for all categories of hospital workers in order to increase their awareness about disaster management.

(2) Need for an enhanced curriculum for nurses in emergency planning and response.

(3) Development of continuing education programmes and in-service education is a necessity.

(4) Graduate programmes in nursing administration and education should include content on disaster preparedness, planning and response related to their role in disaster.

(5) Nursing research in disaster and disaster nursing is necessary in order to provide information to make evidenced-based decisions regarding practice and education.

(6) Replication of this study on all health care workers at hospital.

\section{CONFlicts OF InTEREST Disclosure}

The authors declare that there is no conflict of interest statement.

\section{REFERENCES}

[1] Nouaouri I, Nicolas J, Jolly D. Disaster management in hospital: sizing critical resources. Journal of Computing. 2012; 4(2): 174-179. Available from: https://www.scribd.com/doc/85799168/Disaster-m anagement-in-Hospital-sizing-critical-resources

Published by Sciedu Press 
[2] Dorsey MD. ICN framework of disaster nursing competencies. 2009 Available from: https://www.scribd.com/doc/250672428/D isaster-Nursing-Competencies

[3] Wisner B, Blaikie P, Cannon T, et al. At Risk - Natural hazards, people's vulnerability and disasters. 2004. Available from: http://en.wikipedia.org/wiki/Natural_disaster

[4] ISDR. International Strategy for Disaster Reduction. Terminology: Basic terms of disaster risk reduction. From International Strategy for Disaster Reduction. Geneva, Switzerland. United Nations. 2009. Available from: http://www .unisdr.org/we/inform/termino logy

[5] WHO. Risk reduction and emergency preparedness: WHO six-year strategy for the health sector and community capacity development. Geneva, Switzerland. 2007. Available from: http://www.who.int/hac/techguidance/preparedn ess/emergency_preparedness_eng.pdf

[6] International Federation of Red Cross and Red Crescent Societies. 2013. Available from: http://www.ifrc.org/en/what-we-do/ disaster-management/about-disasters/what-is-a-dis aster/

[7] Stanhope M, Lancaster J. Publish health nursing, population centered health care in the community. 7th ed., Canada: Mosby Elsevier; 2008; 545-455.

[8] Mehta S. Disaster and mass casualty management in a hospital: How well are we prepared? J Postgrad Med. 2006; 52(2): 89-90. Available from: https://www.scribd.com/doc/209102166/Disaste rs-and-Mass-Casualties-Management-in-a-Hospitals PMid:16679668

[9] National Incident Management System [NIMS]. A history of the incident command system. 2004.

[10] Savoia E, Preston J, Biddinger PD. A consensus process on the use of exercises and after action reports to assess and improve public health emergency preparedness and response. Prehosp Disaster Med. 2013; 28(3): 305-308. PMid:23537693 http://dx.doi .org/10 $1017 /$ S1049023X13000289

[11] Hassmiller SB, In Stanhope M, Lancoster J. Centered health care in the community, 17th ed., Canada: Mosby El Sevier; 2008; 455.

[12] Milsten A. Hospital responses to acute onset disasters: A Review. Fellow in Emergency Medical Services. Prehosp Disaster Med. 2000; 15(1): 32-45. PMid:11066840

[13] Bagaria J, Heggie C, Abrahams J, et al. Evacuation and Sheltering of Hospitals in Emergencies: A Review of International Experience. Prehospital and Disaster Medicine. 2009; 24: 461-467. PMid:20066652

[14] Carolyn J. Disaster planning report of tornado casualties. Journal of Kansas Medical Society. 2006; 68: 153.

[15] Lundy KS, Janes SH. Community health nursing: Caring for the public's health. Boston: Jones and Bartlett Publishers; 2001; 558.

[16] Arbon P, Bobrowski C, Zeitz K, et al. Australian nurses volunteering for the Sumatra-Andaman earthquake and tsunami of 2004: A review of experience and analysis of data collected by the Tsunami Volunteer Hotline. Australas. Emerg. Nurs. J. 2006; 9: 171-178. http://dx.doi.org/10.1016/j.aenj. 2006.05.003

[17] Weiner E, Irwin M, Trangenstein P, et al. Emergency preparedness curriculum in US nursing schools, Survey Results. Nursing Education Perspectives. 2005; 26(6): 334-339. PMid:16429998

[18] Fulmer T, Portelli F, Foltin G, et al. Organization-based incident management: Developing a disaster volunteer role on a university campus. Disaster Management and Response. 2007; 5(3): 74-81. Available from: http://www.sciencedirect.com/science/ar ticle/pii/S1540248707000739 PMid:17719508 http://dx.d oi.org/10.1016/j.dmr.2007.06.001
[19] Loke AY, Fung OWM. Nurses' Competencies in Disaster Nursing: Implications for Curriculum Development and Public Health. Int. J. Environ. Res. Public Health. 2014; 11(3): 32893303. PMid:24658409 http://dx.doi.org/10.3390/ijerph1 10303289

[20] Chimenya GT. Hospital Emergency and Disaster Preparedness: A Study of Onandjokwe Lutheran Hospital, Northern Namibia, Submitted in partial fulfillment of the requirements for the degree Masters in Disaster Management. In the Disaster Management Training and Education Center for Africa. 2011.

[21] Veenema T. Essentials of disaster planning. In T. Veenema (Ed.), Disaster nursing and emergency preparedness for chemical, biological, and Radiological terrorism and other hazards New York: Springer Publishing Company; 2007.

[22] Moabi. Knowledge, Attitudes and Practices of Health Care Workers Regarding Disaster Preparedness at Johannesburg Hospital in Gauteng Province, South Africa. In partial fulfillment of the requirements for the degree of Master of Public Health. Faculty of Health Sciences, University of the Witwatersrand, Johannesburg; 2008.

[23] International Federation of Red Cross and Red Crescent Societies (IFRC). Disaster Preparedness Training Programme modules. Disaster Preparedness office, Geneva. 2000. Available from: http://ww w. ifrc.org/Global/Publications/disasters/all.pdf

[24] Mostafa GM. Developing nursing disaster plan for the emergency hospital at Mansoura University. Unpublished Doctoral Thesis. Faculty of Nursing, Mansoura University. Egypt; 2003.

[25] Abd Elazeem H, Adam S, Mohamed G. Awareness of Hospital Internal Disaster Management Plan among Health Team Members in a University Hospital. Life Science Journal. 2001; 8(2): 42-52.

[26] Jahangiri K, Izadkhah YO, Montazeri A, et al. People's perspectives and expectations on preparedness against earthquakes: Tehran case study. Journal of injury and Violence Research. 2010 Jun; 2(2): 85-91. Available from: http://www.ncbi.nlm.nih.g ov/pubmed?term=People's $\% 20$ perspectives $\% 20$ and $\% 20$ e xpectations $\% 20$ on $\% 20$ preparedness $\% 20$ against $\% 20$ earthq uakes $\% 3 \mathrm{~A} \% 20 \mathrm{Tehran} \% 20$ case $\% 20$ studyPMid: 21483203 http: //dx.doi.org/10.5249/jivr.v2i2.25

[27] Ibrahim SA, El Hosany WA. Nurses Awareness Regarding Disasters' Preparedness at Suez Canal University Hospital, Zagazig Nursing Journal. 2010 January; 6(10): 18-27.

[28] Sinha A, Pal DK, Kasar PK, et al. "Knowledge, attitude and practice of disaster preparedness and mitigation among medical students", Disaster Prevention and Management. An International Journal. 2008; 17(4): 503-507. Available from: http://www. emeraldinsight.c om/journals .htm?articleid=1742500\&show=pdf

[29] Samantha MC, Pang RN, Sunshine SS, et al. Pilot training program for developing disaster nursing competencies among undergraduate students in China. Nursing and Health Sciences journal. 2009 December; 11(4): 367-373.

[30] Zhang M, Yu G, Cheng S, et al. Training investigation of hospital nurses on disaster nursing, IT in Medicine and Education (ITME), International Symposium. 2011; 2: 144-147. Available from: http://ieeeexplore.com/xpl/articleDetails.jsp?tp= \&arnumber=6132076\&searchWithin\%3Dp_Authors\%3A.QT . Zhang+Mengna.QT . \%26searchWithin\%3Dp_Author_Ids\%3A3 8233714800

[31] Hokrani B. "Effectiveness of structured teaching program on knowledge of students regarding disaster preparedness at selected pre university colleges of Hassan Karnataka." 1st year M sc nursing community health nursing, Rajiv gandhi university of health sciences, Bangalore, Karnataka. 2011. 
[32] Mangala AJ, Ahirrao A. Effectiveness of Information Booklet on Knowledge about Disaster Preparedness. Sinhgad e-Journal of Nursing. 2012 June; 1: 7.

[33] Ahayalimudin NA, Ismail A, Saiboon IM. Disaster management: a study on knowledge, attitude and practice of emergency nurse and community health nurse. BMC Public Health. 2012; 12(Suppl 2): A3. Available from: http: //www. biomedcentral . com/1471-2458/12/S2/A3http: //dx.doi.org/10.1186/1471-2458-12-S2-A3

[34] Olivia WM, et al. Disaster preparedness among Hong Kong nurses. Journal of Advanced Nursing. 2008; 62(6): 698-703. PMid:18503654 http://dx.doi.org/10.1111/j.1365-2648.2008.04655.x

[35] Yang YN, Luo Y, Liu XN, et al. Research of disaster response capabilities and its influencing factors of community nurses in Chongqing municipality. Journal of Nursing Administration. 2010; 10: 698-699.

[36] Al Khalaileh MA, Bond E, Alasad JA. Jordanian nurses' perceptions of their preparedness for disaster management. International Emergency Nursing. 2012; 20: 14-23. PMid:22243713 http://dx.doi .org/10.1016/j.ienj.2011.01.001

[37] Collander B1, Green B, Millo Y, et al. Development of an "allhazards" hospital disaster preparedness training course utilizing multi-modality teaching. Prehosp Disaster Med. 2008; 23(1): 6369. Available from: http://www.ncbi.nlm.nih.gov/pubmed/ 18491664?dopt=Citation

[38] Campbell AT, Hart KD, Norton SA. Legal and ethical issues in disaster responses. In Veenema T. G., Disaster nursing and emergency preparedness for chemical, biological, and radiological terrorism and other hazards.(2nd ed). New York, NY: Springer Publishing; 2007; 100-116.

[39] O'Sullivan TL, Dow D, Turner MC, et al. Disaster and emergency management: Canadian nurses' perceptions of preparedness on hospital front lines. Prehosp Disaster Med. 2008; 23(3): 11-8.

[40] Chagutah T. Towards improved public awareness for climate related disaster risk reduction in South Africa: A participatory development communication perspective. JAMBA. 2009 November; 2: 113. http://dx.doi.org/10.4102/jamba.v2i2.19
[41] Mohamed N, Zakaria A. Maintaining a safety environment in hospital. The first international conference on clinical engineering: Safety in hospital environment. 2003.

[42] Hick JL, Hanfling D, Burstein JL, et al. Health Care Facility and Community Strategies for Patient Care Surge Capacity. The American College of Emergency Physicians. Annals of Emergency Medicine. 2004; 44: 253-261. PMid:15332068 http://dx.doi.org/10.10 16/j.annemergmed. 2004.04.011

[43] Rebmann T, Wilson R, LaPointe S, et al. Hospital infectious disease emergency preparedness: A 2007 survey of infection control professionals. Am J Infect Control. 2008. http://dx.doi.org/10.10 16/j.ajic.2008.02.007

[44] Kaji AH, Lewis RJ. Hospital Disaster Preparedness in Los Angeles County. Academic Emergency Medicine. 2006; 13: 1198-1203. ht tp://dx.doi.org/10.1111/j.1553-2712.2006.tb01648.x

[45] Liu QQ, Li RQ, Geng XW, et al. Survey of status quo of nurses' cognition level and attitudes to disaster nursing. Chinese Nursing Research. 2011; 25: 3028-3030.

[46] Goyal M, Kohli C, Kishore J, et al. Effect of an Educational Booklet on Knowledge and Attitude Regarding Major Depressive Disorder in Medical Students in Delhi. International Journal of Medical Students. 2013; 1(1). Available from: http://www.ijms.info/ojs/inde $\mathrm{x} \cdot \mathrm{php} / \mathrm{IJMS} /$ article/view/7\#. VTL88PBEWT4

[47] Safan SM. Self Learning Package as a Mean for Achieving Quality Nursing Documentation at Shebin El-Kom University Hospital. Unpublished Doctoral Thesis. Faculty of Nursing, Menoufia University. Egypt. 2008.

[48] Jiang L, He HG, Zhou WG, et al. Knowledge, attitudes and competence in nursing practice of typhoon disaster relief work among Chinese nurses: A questionnaire survey. International Journal of Nursing Practice. 2015; 21: 60-69. PMid:24219840 http://dx.d oi.org/10.1111/ijn.12214

[49] Lai .FC, Lei HM, Fang CM, et al. Disaster nursing and primary school teachers' disaster-related healthcare knowledge and skills. $\mathrm{Hu}$ Li Za Zhi. The journal of nursing. 2012; 59(3): 16-22. Available from: http://www.ncbi.nlm.nih.gov/pubmed/22661028 